\title{
Formação de Educadoras (es) Ambientais como lugar de resistência: uma concepção de natureza aliada aos interesses da classe trabalhadora
}

\author{
Formación de Educadoras (es) Ambientales como lugar de resistencia: \\ una concepción de naturaleza aliada a los intereses de la clase obrera
}

\author{
Training of Environmental Educators (es) as a place of resistance: a \\ conception of nature allied with the interests of the working class
}

\author{
Darlene Silveira Cabrera ${ }^{1}$ \\ Alex Nunes Molina ${ }^{2}$ \\ Luis Fernando Minasi ${ }^{3}$
}

\begin{abstract}
Resumo
O presente artigo compila os resultados de uma pesquisa, a qual teve como fundante a compreensão de Educação Ambiental como espaço de resistência frente aos imperativos do modo de produção capitalista, bem como se coloca como práxis de denuncia e enfrentamento aos e dos retrocessos socioambientais organizados pelos desgovernos locais e globais. Dessa forma, o trabalho se caracteriza por uma pesquisa qualitativa, subsidiada pela metodologia de pesquisa bibliográfica e desenvolvida no Campo da Educação Ambiental. Para tanto, objetivou discutir e refletir sobre a concepção de natureza como questão sine qua non do desenvolvimento da Formação de Educadoras (es) Ambientais como lugar de enfretamento da Crise Ambiental (MÈSZÀROS, 2008; 2011) que imergimos. Assim, as reflexões resultantes da pesquisa são apresentadas, primeiro, seguindo um eixo histórico sobre como se desenvolveu a concepção de natureza e de que forma essa pode vir a influenciar o que estamos compreendendo por Educação Ambiental e por Formação de Educadoras (es) Ambientais, considerando a relação ininterrupta entre natureza - ser humano - ser humano - natureza. Em seguida, os resultados e discussões, afirmam o conceito de natureza referenciado em Karl Marx (2004; 2010; 2012; 2013) como uma das possibilidades de constituição da Educação Ambiental almejada aliada aos interesses da classe trabalhadora, a compreendendo a partir das imbricações entre: natureza natural; natureza humana; e natureza humanizada.
\end{abstract}

Palavras-Chave: Concepção de natureza; Educação Ambiental; Enfrentamento ao modo de produção; Formação de Educadoras (es) Ambientais

\section{Resumen}

El presente artículo compila los resultados de una investigación, la cual tuvo como fundante la comprensión de Educación Ambiental como espacio de resistencia frente a los imperativos del modo de producción capitalista, así como se plantea como praxis de denuncia y enfrentamiento a los y de los retrocesos socioambientales organizados por los ciudadanos desgobernadores locales y globales. De esta forma, el trabajo se caracteriza por una investigación cualitativa, subsidiada por la metodología de investigación bibliográfica y desarrollada en el Campo de la Educación Ambiental. Para ello, objetivó discutir y reflexionar sobre la concepción de naturaleza como cuestión sine qua non del desarrollo de la Formación de Educadoras (es) Ambientales como lugar de enfrentamiento de la Crisis Ambiental (MÉSZÁROS, 2008; 2011) que sumergimos. Así, las reflexiones

\footnotetext{
1 Doutoranda em Educação Ambiental pelo PPGEA - FURG; Rio Grande; RS; Brasil; Financiamento: Coordenação de Aperfeiçoamento de Pessoal de Nível Superior - CAPES; darlenescabrera@gmail.com

${ }^{2}$ Mestrando do Programa de Pós-Graduação em Educação Ambiental na Universidade Federal do Rio Grande (FURG), Rio Grande; RS; Brasil; molina.quimica@gmail.com

${ }^{3}$ Doutor em Educação pela UFRGS; Porto Alegre; RS; Brasil; lfminasi@gmail.com
} 
resultantes de la investigación se presentan, primero, siguiendo un eje histórico sobre cómo se desarrolló la concepción de naturaleza y de qué forma puede influir en lo que estamos comprendiendo por Educación Ambiental y por Formación de Educadoras (es) Ambientales, considerando la relación ininterrumpida entre naturaleza - ser humano - ser humano - naturaleza. A continuación, los resultados y discusiones, afirman el concepto de naturaleza referenciado en Karl Marx (2004; 2010; 2012; 2013) como una de las posibilidades de constitución de la Educación Ambiental deseada aliada a los intereses de la clase obrera, comprendiendo a partir de las imbricaciones entre : naturaleza natural; naturaleza humana; y la naturaleza humanizada.

Palabras claves: Concepción de naturaleza; Educación ambiental; Enfrentamiento al modo de producción; Formación de Educadoras (es) Ambientales

\begin{abstract}
The present article compiles the results of a research, which was based on the understanding of Environmental Education as a space of resistance against the imperatives of the capitalist mode of production, as well as posing as a praxis of denunciation and confrontation with the social and environmental setbacks organized by the local and global mismanagement. In this way, the work is characterized by a qualitative research, subsidized by the methodology of bibliographic research and developed in the Field of Environmental Education. In order to do so, it aimed to discuss and reflect on the conception of nature as a sine qua non issue of the development of the Environmental Educators' Training as a place of confrontation of the Environmental Crisis (MÈSZÀROS, 2008; 2011) that we immerse. Thus, the reflections resulting from the research are presented, first, following a historical axis on how the conception of nature has developed and in what way it may influence what we are understanding by Environmental Education and Training of Environmental Educators, considering the uninterrupted relationship between nature - human being - human being - nature. Then, the results and discussions affirm the concept of nature referred to in $\operatorname{Karl} \operatorname{Marx}(2004,2010,2012,2013)$ as one of the possibilities for the constitution of Environmental Education aimed at allied to the interests of the working class, understanding from the interlinkages between : natural nature; human nature; and humanized nature.
\end{abstract}

Keywords: Conception of nature; Environmental education; Coping with the mode of production; Training of Environmental Educators

\title{
1. Introdução
}

O presente artigo é um ensaio teórico organizado a partir de uma das premissas do Campo da Educação Ambiental: espaço de resistência frente aos imperativos do capital. Dessa forma, almejamos discutir e refletir, tendo como subsídio alguns apontamentos neste breve espaço textual que compõe um artigo, sobre como se desenvolveu a concepção de natureza e de que forma essa compreensão sobre a natureza pode vir a influenciar o que estamos compreendendo por Educação Ambiental, considerando sua relação ininterrupta entre natureza - ser humano - ser humano - natureza.

Consideramos a pertinência dessa discussão por concebermos a conjuntura atual enquanto uma Crise Ambiental que se alicerça no modo de produção capitalista - o qual configura uma consciência social para manutenção da ordem estabelecida. Tal crise impregna todos os meandros sociais, afeta as bases fundamentais da sobrevivência humana: a natureza natural, bem como impera sobre as relações sociais ditando os modus de ser e existir, logo estamos concebendo a Crise Ambiental como Crise Estrutural do Capital (MÈSZÀros, 2011). 
Para tanto, como forma de enfrentamento deste contexto histórico que nos inserimos, estamos concebendo a possibilidade de constituir no Campo da Educação Ambiental um projeto de sociedade que zele pela vida humana e por suas condições de sobrevivência, questionador da legitimidade da ação política em prol dos imperativos do capital. Trata-se de um projeto social que intenta preservar os espaços da crítica sobre o modelo sociedade em desenvolvimento.

Assim sendo, intentamos discutir e refletir sobre um dos conceitos fundantes da Educação Ambiental: a concepção de natureza. Portanto, organizamos o presente texto da seguinte forma: (a) uma breve introdução - para melhor compreensão da temática e dos nossas premissas teóricas; (b) apontamentos sobre a dinâmica histórica em que vem se constituindo a concepção de natureza e suas imbricações com a constituição da Educação Ambiental; (c) o que estamos compreendendo por natureza e como isso contribui para pensar a Educação Ambiental e a Formação de Educadoras (es) Ambientais aliada aos interesses a classe trabalhadora; e (d) algumas considerações sobre esse processo dessa pesquisa.

\section{Um histórico da constituição da concepção de natureza}

Começaremos por situar no geral o movimento que as diferentes concepções de natureza tiveram ao longo da história, compreensões essas que influenciaram diretamente as relações travadas entre os seres humanos e o meio onde se inserem. Compreendemos, então, que assim como o processo de constituição histórico da humanidade, o processo de constituição da concepção de natureza não ocorre de forma linear, mas sim de maneira dinâmica e articulada na materialidade.

Partindo do século XV, observamos que a natureza era vislumbrada como algo externo à vida humana, de forma que a legislação da época, por exemplo, incentivava a caça de animais silvestres no sentido de exterminá-los, bem como instigava os seres humanos à devastação das matas nativas, tendo como ideal civilizatório o êxodo rural. Latente, entre os homens, era o sentimento de desprezo e selvageria em relação à natureza, conforme evidencia Thomas More, diplomata inglês ocupante de diversos cargos políticos que viveu até 1535, ao dizer que a natureza tem como única utilidade suprir as necessidades humanas (THOMAS, 1989).

Por conseguinte, no século XVI, uma das proposições que encontramos sobre a relação ser humano-natureza está nos postulados do filosofo Francis Bacon, o qual propõe "dominar a Natureza pelo saber, a fim de converter nosso conhecimento em algo útil e proveitoso a vida dos homens (JAPIASSU, 1995, p.5)". Bacon destaca a importância da 
capacidade técnica e do desenvolvimento do conhecimento humano para que seja possível intervir na natureza, explicitando a relação do saber com o poder.

Tal período, influenciado pelo pensamento de Bacon - um dos precursores do método científico - tendeu a avaliar a verdade da ciência ligada à habilidade de domínio dos recursos naturais, da natureza (GRÜN, 2006). Para tanto, seu modelo de ciência no decorrer da modernidade anuncia a concepção do conhecimento moderno, tendo seus desdobramentos nas dicotomias corpo e mente; sujeito e objeto; razão e emoção e homem e natureza, negando a natureza como parte inerente a todas as mulheres e homens.

Nessa perspectiva, de distinção entre as unidades; como corpo e alma, natureza e cultura; no século XVII filosofo Descartes atribui à natureza definição simplesmente de espaço e despe de significado e valor a relação com o lugar. O fillosofo francês propõe o uso utilitarista da natureza a partir de uma filosofia prática, de acordo com a qual nos tornaríamos "senhores e possuidores da natureza" (DESCARTES, 1998, p.79).

Ao final do século XVII e início do século XVIII surge a necessidade de retornar para o campo almejando uma vida mais saudável. Isso ocorre devido ao contexto de degradação da natureza natural causado pela Revolução Industrial, onde as doenças endêmicas e a violência urbana eram elementos que já afetavam também a classe burguesa.

Nesse cenário, o ideário de maiores cuidados com o ambiente natural é disseminado, assim como a propagação da ideia que tendo um ambiente natural preservado seria possível o acesso ao ar puro e a tranquilidade estimada para o descanso e a recuperação de doenças. Sob influência do pensamento do economista britânico Thomas Malthus, a natureza - ainda considerada externa ao homem - passa a ser presumida como benéfica à vida humana e as paisagens passam a ser contempladas, dando status de sortilégio à burguesia, minoria que tinha acesso a esse bem (THOMAS, 1989).

Atrelado, ao constructo filosófico do século XVIII, constitui-se o ideário de natureza, enquanto instância pedagógica, embasado no pensamento do educador e filósofo suíço JeanJacques Rousseau, igualmente conhecido como um dos precursores do iluminismo. Rousseau desenvolveu seu pensamento na perspectiva de um projeto de educação conforme as leis da natureza, porém seguir a ordem da natureza denotava retornar à vida primitiva e encontrar a verdadeira natureza que corresponde à vocação humana.

Como corrobora Nadja Hermann (2006), Rousseau retorna à natureza na tentativa de manter a unidade entre o homem e o universo: 
nossa natureza, o homem não pode ser são de espirito nem bem constituído senão na medida em que é bom (HERMANN, 2006, p. 94).

Rousseau apostava na interioridade humana enquanto natureza humana, portanto afirmava uma pedagogia naturalista colocando como centralidade do processo de ensino e aprendizagem a criança, o jovem e a natureza (HERMANN, 2006). O filósofo e educador assegurava a necessidade de educar a partir dos interesses naturais do aluno, não suprimindo os sentidos, as emoções, os instintos e os sentimentos, os quais eram considerados por ele como anteriores ao pensamento racional, assim auxiliando a preservar a natureza das crianças e dos jovens.

Indubitavelmente, no século XIX, destacamos a teoria social desenvolvida pelo filosofo alemão Karl Marx e a relação dessa com a concepção de natureza. De forma que, entendemos nesse constructo filosófico a natureza como questão fundante, a qual consideramos como uma contribuição indispensável à Educação Ambiental.

De tal modo, Marx nos ressalta suas concepções acerca das relações entre natureza ser humano - ser humano - natureza, mediadas pelo trabalho.

\begin{abstract}
Antes de tudo, o trabalho é um processo entre o homem e a natureza, um processo em que o homem, por sua própria ação, media, regula e controla seu metabolismo com a natureza. Ele mesmo se defronta com a matéria natural como uma força natural. Ele põe em movimento as forças naturais pertencentes à sua corporeidade, braços e pernas, cabeça e mão, a fim de apropriar-se da matéria natural numa forma útil para sua própria vida. Ao atuar, por meio desse movimento sobre a natureza externa a ele e ao modificá-la, ele modifica, ao mesmo tempo, sua própria natureza. (MARX, 2004, p. 36).
\end{abstract}

Compreendemos, a partir de Marx, a natureza natural como matéria prima do trabalho humano, a qual o ser humano transforma através do trabalho e simultaneamente transforma a si. Assim, ao passo que o homem se transforma mediado pelo trabalho, às múltiplas formas como ele se relaciona com a natureza, que lhe é externa, também são transformadas.

Já nas décadas de 1940, 1960 e 1970, do século XX, as articulações feitas sobre a natureza - concebida somente enquanto externalidade humana - têm início devido à preocupação da Organização das Nações Unidas - ONU com a acelerada extinção da fauna e da flora, e, em seguida, com o exacerbado consumo dos meios de produção ${ }^{4}$. A partir de uma análise dos documentos oficiais que representam internacionalmente a questão ambiental mundial observamos que a Educação Ambiental é eleita, pelos organismos internacionais, como a solução para melhor gerir as relações entre o homem e a natureza.

\footnotetext{
${ }^{4}$ Terminologia utilizada por Marx em o Capital, livro I, de 2013 para designar os meios usados pelos homens para produção dos bens necessários à reprodução material da vida humana e da sociedade como um todo.
} 
Em consequência disso, em âmbito nacional, foi organizada a Política Nacional do Meio Ambiente, de 1981, a qual tem enquanto centralidade o meio ambiente definido como "o conjunto de condições, leis, influências e interações de ordem física, química e biológica, que permite abrigar e reger a vida em todas as suas formas (§ I, Art. 3º, BRASIL, 1981)”. Portanto, a discussão sobre natureza, nesse período no Brasil, é influenciada pela concepção em âmbito mundial, a qual visa orientar o homem na esfera da diminuição do consumo disseminando o discurso de preservação dos bens e dos recursos da natureza natural.

Nesse sentido, é promulgada em seguida, em nosso país, a Constituição Federal brasileira em 1988, designando em seu Artigo $225^{\circ}$ o meio ambiente ecologicamente equilibrado como um direito de todos, além de comprometer-se [o Estado, o Poder Público] a defender e preservar esse bem da coletividade por meio da restauração dos processos ecológicos, das espécies e dos ecossistemas; da preservação e fiscalização da biodiversidade genética; da proteção dos territórios, da fauna e da flora e do controle da extração do meio ambiente (BRASIL, 1988).

Tal noção unívoca sobre a natureza: meio ambiente natural, disseminada pelos documentos legais brasileiros e atrelada ao desejo de desacelerar os prejuízos sociais causados pela degradação ambiental durante muitos séculos, influenciam discussões acerca das medidas a serem tomadas para que o homem continuasse a usufruir dos bens naturais sem o risco de extingui-los.

Compreendemos, a partir de Layrargues (1998), que esse contexto econômico, político, cultural vivido pela humanidade desponta como elemento estruturante para dar novos sentidos à relação com a natureza. Assim, grupos que se ocupavam da questão ambiental organizam eventos e produções bibliográficas, as quais resultaram em documentos que compõem o sistema jurídico-legal em âmbito nacional, onde sistematizam os pressupostos ambientais brasileiro.

Ademais, podemos compreender a partir das análises de Cabrera (2016) que as Políticas Públicas que versam sobre a questão ambiental, em âmbito internacional e nacional, entre o período de 1949 a 2015, centram - se em uma concepção unívoca do que vem a ser a questão ambiental até a década de 1990. Não obstante, podemos evidenciar até esse período [1990] a consolidação do debate ambiental apenas em torno das temáticas de desperdício e escassez dos recursos naturais, isto é, tendo como subsídio a concepção de natureza apenas como meio natural.

Contudo, a discussão ambiental engendra a dimensão humano-social em 1992, com o Tratado de Educação Ambiental para as Sociedades Sustentáveis e Responsabilidade Global, 
o qual reconhece a Educação Ambiental como um processo educativo dinâmico e permanente na transformação humana e social (BRASIL, 1992). Para tanto, traz como princípio o trabalho com a Educação Ambiental, visando o enfoque do ser humano, do universo e da natureza de forma interdisciplinar e o tratamento de questões globais suas causas e inter-relações a partir do seu contexto sócio- histórico.

\section{Uma concepção de natureza aliada aos interesses da classe trabalhadora}

Afirmamos a Educação Ambiental, enquanto proposta centrada nas relações humanas, nas condições de existência social e material do homem, tornando evidente que a forma de produção da vida social é consequência das relações econômicas vigentes. Elencamos uma Educação Ambiental que denuncie as formas de relações humanas pautadas por um sistema sustentado sobre uma base econômica, que coloca a natureza apenas como externalidade humana, ou seja, afirmamos uma Educação Ambiental que conceba o homem também enquanto natureza (MARX, 2010).

Sustentamos, assim, a Educação Ambiental, bem como a Formação de Educadoras (es) em uma perspectiva crítica referenciada pela concepção de natureza em Marx como possibilidade de "estratégia político-pedagógica para emancipação dos sentidos humanos acerca dos fundamentos do modo de produção material de nossa sociedade" (CRUZ, BIGLIARDI e MINASI, 2013, p.103).

Respaldados por esse referencial, compreendemos a Educação Ambiental como possibilidade de superação do modo de produção vigorante e das formas atuais de sociabilidade humana, para uma sociedade - como nos chama atenção Marx (2012) e, posteriormente, Mészáros (2008) - de igualdade substantiva. Sociedade essa, em que os seres humanos serão reconhecidos na sua individualidade, poderão contribuir socialmente na medida de suas capacidades e receberão da sociedade ao grau de suas necessidades.

Sociedade essa, em que os seres humanos se identificarão como natureza ao passo que se constituem sociais pelo trabalho. Uma vez que é através do trabalho que o homem transforma a natureza natural e é no processo de trabalho que se dá sua transformação de ser natural para ser humano social, sendo por meio da atividade criativa do homem - o trabalho que acontece no biológico a formação social, ou seja, a constituição do natural ao humanosocial (MARX, 2010).

Concebemos o trabalho como uma atividade vital à existência humana, enquanto atividade criativa que produz a sociedade e desenvolve a educação (KONDER, 2008), 
consideramos de extrema relevância pensar o trabalho atrelado às práticas de ensinoaprendizagem da Formação de Educadoras (es). Práticas criadoras definidas como

aquelas que permitem aos seres humanos agir sobre a natureza e transformá-la em função de seus objetos próprios e, pelo mesmo ato, transformarem-se a si mesmo. [...] transformar a natureza significa conferir-lhe uma "forma" nova de existência material e simbólica (SIRGADO, 2000, p.50).

Logo, compreendemos que a Educação Ambiental ao se constituir como um processo de socialização dos indivíduos em uma determinada cultura tem na práxis a forma de humanização dos seres humanos em sociedade. Pois, nascemos como seres naturais, e é na convivência - onde implica interação, interferência com os outros seres humanos e com a natureza natural, externa a nós - que acontece a humanização. Isto é, nós enquanto seres inconclusos na busca pela vocação ontológica de "ser mais", estamos em permanente movimento à procura de conhecimentos e respostas sobre nós e sobre o mundo para solução de problemas (FREIRE, 2014). Compreendemos, assim, que é nessa incessante busca, mediados pelos processos da educação, que nos humanizamos.

Alegamos, dessa forma, que a Educação Ambiental em sua totalidade é indissociável da perspectiva de classe. Sendo assim, serve tanto de instrumento para a manutenção das condições de exploração e subordinação do modo de produção vigente, quanto de alavanca para a necessária transformação histórica da sociedade.

Estamos considerando a Educação Ambiental como possibilidade de nos desvencilharmos do modelo ditatorial do capitalismo desde que atrelada à moção da classe dos trabalhadores, engajados à redefinição do atual molde econômico, ditador das regras civilizatórias. Assim, em consonância com Goergen (2014), compreendemos que os múltiplos esforços da Educação Ambiental são fundamentais e imprescindíveis enquanto estratégia na luta contra o imperialismo do capital, no entanto não são somente as pequenas intervenções no montante da cadeia plural de posturas epistêmicas, éticas e econômicas que redefinirão problemas sistêmicos, conjecturados ao modelo de desenvolvimento ramificado nos últimos duzentos ou trezentos anos.

Para tanto, ainda na esteira do que nos propõe Goergen (2014), o grande desafio à Educação Ambiental se põe no sentido de trabalhar como parte integrante de um esforço maior que propende à transformação radical do modo de produção e a reorientação da sociabilidade humana. Haja vista, que as intervenções educativas parcelares, tópicas, disciplinares - as quais consideramos como as práticas possíveis hoje - que se efetivam nas brechas deixadas pelo metabolismo do capital, só contribuirão para sociedade que almejamos, se forem fundadas na compreensão de mundo enquanto totalidade. 
Assim, a compreensão de mundo enquanto totalidade está intimamente ligada à concepção de natureza, pautada no pensamento de Karl Marx (2004; 2010; 2012; 2013). A vista disso, a Educação Ambiental deve cumprir o seu papel fundamental pedagógico e impulsionador de outra sociabilidade humana, de modo que forme Educadoras (es), também, para compreensão da Crise Ambiental enquanto totalidade.

Ao passo que com mais perspicácia desvelamos as relações sociais, desenvolvemos então certa aproximação com a compreensão de totalidade, que almejamos com a efetivação da Educação Ambiental, conforme nos evidencia Lukács.

Pois a meta final não é um estado que aguarda o proletariado ao termo do movimento, independente deste e do caminho que ele percorre, como um "estado futuro"; não é um estado que se possa, por conseguinte, esquecer tranquilamente nas lutas cotidianas [...] A meta final é, antes de tudo, essa relação com a totalidade (com a totalidade da sociedade considerada como processo), pela qual cada momento da luta adquire seu sentido revolucionário (LUKÁCS, 2003, p.101).

Concebemos, portanto, a Educação Ambiental subsidiada pela compreensão de totalidade da realidade objetiva, como a forma possível de aguçar em mulheres e homens a capacidade de sentir, compreender e conceituar a realidade nas suas mais variadas formas e múltiplas ligações, possibilitando desenvolver a noção de ser humano enquanto sujeito histórico.

Ao refletirmos sobre a Educação Ambiental tendo como proposições a formação humana para compreensão da totalidade objetiva do mundo, ressaltamos a necessidade desenvolver o conceito de natureza como fundamento teórico significativo a tal formação. Portanto, consideramos que a concepção de natureza desenvolvida nos postulados de Karl Marx $(2004 ; 2010 ; 2013 ; 2012)$ é uma das possibilidades latente ao processo formativo almejado pela Educação Ambiental.

Para tanto, Marx (2013) em sua obra, afirma que

como criador de valores de uso, como trabalho útil, é o trabalho, por isso, uma condição de existência do homem, independentemente de todas as formas de sociedade, eterna necessidade natural de mediação do metabolismo entre homem e natureza e, portanto, vida humana (MARX, 2013, p. 50).

Nessa obra Marx (2013) elaborou significativa contribuição à concepção de natureza, a partir da qual podemos compreender que há uma insuprível relação do ser social com os recursos naturais, e concomitantemente com produção da própria natureza humana, tal relação é chamada por ele como mediação do metabolismo do ser humano com a natureza. Destarte, o trabalho e a sua forma de organização constituem-se como centralidade no processo sociometabólico em seu permanente movimento em consonância com a natureza. 
Corroborando, ainda, com o desenvolvimento da concepção de natureza em Marx como uma das possibilidades de fundamentação teórica consistente à Educação Ambiental, Bellamy Foster (2005) aponta que

O conceito de metabolismo, com suas noções subordinadas de trocas materiais e ação regulatória, permitiu que ele expressasse a relação humana com a natureza como uma relação que abrangia tanto as "condições impostas pela natureza" quanto à capacidade dos seres humanos de afetar este processo (FOSTER, 2005, p. 223).

Compreendemos, então, que o constructo filosófico constituído por Marx estabeleceu a natureza na relação permanente com trabalho mediado pela ação da natureza humana - o ser humano. Bem como, também, pode ser compreendido na obra Manuscritos EconômicoFilosóficos que "o trabalho é a condição natural do gênero humano, a condição independentemente de qualquer forma social - da troca de substância entre o homem e a natureza" (MARX, 2010, p. 22).

\section{Nossas considerações}

Consideramos que nos encontramos em um estágio avançado da Crise Ambiental enquanto Crise Estrutural do Capital - em que a continuidade do "progresso" capitalista fundado na economia ameaça a sobrevivência da espécie humana no planeta (COGGIOLA, 2004). O acréscimo desmedido das agressões feitas ao meio em que vivemos leva-nos a crer em uma ruptura, próxima, dos sistemas ecológicos, configurando uma atmosfera catastrófica que põe em risco a vida humana na terra.

Referimo-nos a uma Crise que se alastra por todos os setores sociais e afeta as bases fundamentais da sobrevivência humana - as relações com a natureza natural. Afirmamos, a partir de Mészáros (2011), que chegamos aos limites históricos da competência do capital para o controle da sociedade, e, dessa forma, temos como única alternativa encontrar outra forma de reprodução social - de sociabilidade humana.

Diante disso, consideramos a Educação Ambiental e no seu cerne a Formação de Educadoras (es), como um dos campos que pode vir a contribuir para a constituição de outro projeto de sociedade, o qual tenha como prioridade os interesses da classe trabalhadora, pautado em relações menos desiguais possíveis entre natureza - ser humano -ser humano natureza. Portanto, compreendemos como questão fundante desse processo explicitar o que estamos compreendendo por natureza.

De tal modo, nos referenciamos nos postulados de Karl Marx, a partir dos quais estamos concebendo a natureza enquanto: natureza natural - externalidade humana; natureza 
humana -natureza como parte constituinte do ser humano; e, natureza humanizada - da relação entre ser humano e natureza natural mediada pelo trabalho resulta a natureza humanizada.

Assim, compreendemos ancorados em Karl Marx, a natureza natural como matéria prima do trabalho humano, a qual o ser humano transforma através do trabalho e simultaneamente transforma a si. Logo, ao passo que a homem se transforma mediado pelo trabalho, às múltiplas formas como ele se relaciona com a natureza que lhe é externa, também são transformadas, dessa forma contribuindo para o processo de outra sociabilidade humana.

\section{Referências}

BRASIL. Constituição da República Federativa do Brasil, de 1988. Disponível em: file://C:/Users/Win7/Downloads/constituicao_federal_35ed.pdf. Acessado em: 26/12/18. (Lei brasileira)

BRASIL. Política Nacional de Meio Ambiente, de 31 de agosto de 1981. Disponível em:〈http://www.sema.rs.gov.br/upload/Lei\%20Federa1\%20n\%C2\%BA\%206938_1981.pdf>. Acessodo em: 18/12/18. (Lei brasileira)

BRASIL. Tratado de Educação Ambiental para as Sociedades Sustentáveis e Responsabilidade Global, de $1992 . \quad$ Disponível: http://portal.mec.gov.br/secad/arquivos/pdf/educacaoambiental/tratado.pdf. Acessodo em: 26/12/18. (Lei brasileira)

CABRERA, Darlene Silveira. A objetivação das Diretrizes Curriculares Nacionais para Educação Ambiental na formação de professores: um estudo de caso no Curso de Pedagogia da FURG. 2016. 198 f. Dissertação (Mestrado em Educação Ambiental) - Universidade Federal do Rio Grande -FURG, Rio Grande, 2012.(Dissertação)

COGGIOLA, Osvaldo. Ecologia e Marxismo. Revista Motrivivência. Ano XVI, nº 22, p. 3946, Junho de 2004. Disponível em: <https://periodicos.ufsc.br/index.php/ motrivivencia/article/.../1183/1887>. Acesso em: 16/12/18. (Artigo em periódico digital)

CRUZ, Ricardo Gautério, BIGLIARDI, Rossane Vinhas, MINASI, Luis Fernando. Crise ambiental e crise do modo de produção: os limites sócio-metabólicos do capital. Revista Eletrônica do Mestrado em Educação Ambiental. Abril 2013. Disponível em: <http://www.seer.furg.br/remea/issue/view/408>. Acesso em: 10/12/18. (Artigo em periódico digital)

DESCARTES. Discurso de método [comentários: Denis Huisman]. Brasília: UnB, 1998. (Obra completa)

FOSTER, John B. A ecologia de Marx: Materialismo e a Natureza. São Paulo: CIV brasileira, 2005. (Obra completa) 
FREIRE, Paulo. Pedagogia do oprimido. 56. ed. Rio de Janeiro: Paz e Terra, 2014. (Obra completa)

GORGEN, Pedro. A ética e o futuro da humanidade: considerações críticas sobre educação ambiental. Revista Pesquisa em Educação Ambiental, vol. 9, n. 1 - pg. 10-23, 2014. Disponível em: http://www.periodicos.rc.biblioteca.unesp.br/index.php/ pesquisa/search /search. Acesso em: 18/12/18. (Artigo publicado em periódico)

GRÜN, Mauro. Bacon: a ciência como conhecimento e domínio da natureza. In: CARVALHO, Isabel C.; GRÜN, Mauro e TRAJBER, Rachel. Pensar o Ambiente: bases filosóficas para Educação Ambiental. Brasília: Ministério da Educação, Secretaria de Educação Continuada, Alfabetização e Diversidade, UNESCO, 2006. (Capítulo de livro)

HERMANN, Nadja. Rousseau: o retorno a natureza. Bases Filosóficas para pensar Educação Ambiental, 2006. Disponível em: <http://portal.mec.gov.br/dmdocuments/ publicacao4.pdf〉. Acesso em: 12/12/18. (Livro virtual)

JAPIASSU, H. Francis Bacon: o profeta da ciência moderna. São Paulo: Letra \& Letras, 1995. (Obra completa)

KONDER, Leandro. Marxismo e Alienação. São Paulo: Expressão Popular, 2008. (Obra completa)

LAYRARGUES, Philippe Pomier. A Cortina de Fumaça: o discurso empresarial verde e a ideologia da racionalidade econômica. São Paulo: Annalume, 1998. (Obra completa)

LUKÁCS, Georg. História e consciência de classe: estudos sobre a dialética marxista. [trad. Rodnei Nascimento, revisão de trad. Karina Jannini]. São Paulo: Martins Fontes, 2003. (Obra completa)

MARX, Karl. Crítica ao Programa de Gota. São Paulo: Boitempo, 2012. (Obra completa)

. Manuscritos econômico-filosóficos. [trad. Jesus Ranieri]. 1.ed. São Paulo: Boitempo, 2010. (Obra Completa)

. Processo de trabalho e Processo de valorização. In: Antunes, Ricardo (org.) $A$ dialética do trabalho. São Paulo: Expressão Popular, 2004. (Capítulo de livro)

O Capital - Livro I. São Paulo: Boitempo, 2013.(Obra completa)

MÉSZÁROS, István. A crise estrutural do Capital. [trad. Francisco Raul Cornejo et al.]. 2.ed. São Paulo: Boitempo, 2011. (Obra completa)

A educação para além do capital. [trad. Isa Tavares]. 2.ed. São Paulo:

Boitempo, 2008. (Obra completa)

SIRGADO, Angel Pino. O social e o cultural na obra de Vigotski. Revista Educação \& Sociedade. V. 21. N.71. Julho de 2000. Disponível em: <http://dx.doi.org/10.1590/ S010173302000000200003>. Acesso em: 12/12/2018. (Artigo publico em periódico) 
RELACult - Revista Latino-Americana de Estudos em Cultura e Sociedade

Revista Latinoamericana de Estudios en Cultura y Sociedad | Latin American Journal of Studies in Culture and Society V. 05, ed. especial, abr., 2019, artigo $n^{\circ} 1103$ | claec.org/relacult | e-ISSN: 2525-7870

THOMAS, Keith. O homem e o mundo natural: mudanças de atitude em relação as plantas $e$ aos animais. São Paulo: Companhia das Letras, 1989. (Obra completa) 